\title{
Rise and fall of total mesorectal excision with lateral pelvic lymphadenectomy for rectal cancer: an updated systematic review and meta-analysis of 11,366 patients
}

\author{
Gabriele Anania ${ }^{1}$ - Richard Justin Davies ${ }^{2}$. Alberto Arezzo ${ }^{3}$. Francesco Bagolini ${ }^{1}$ (D) Vito D'Andrea ${ }^{4}$. \\ Luigina Graziosi $^{5}$. Salomone Di Saverio ${ }^{6} \cdot$ Georgi Popivanov $^{7} \cdot$ Isaac Cheruiyot ${ }^{8} \cdot$ Roberto Cirocchi $^{5}$. \\ Annibale Donini ${ }^{5}$
}

Accepted: 26 April 2021 / Published online: 14 June 2021

(C) The Author(s) 2021, corrected publication 2021

\begin{abstract}
The role of lateral lymph node dissection (LLND) during total mesorectal excision (TME) for rectal cancer is still controversial. Many reviews were published on prophylactic LLND in rectal cancer surgery, some biased by heterogeneity of overall associated treatments. The aim of this systematic review and meta-analysis is to perform a timeline analysis of different treatments associated to prophylactic LLND vs no-LLND during TME for rectal cancer.

Methods A literature search was performed in PubMed, SCOPUS and WOS for publications up to 1 September 2020. We considered RCTs and CCTs comparing oncologic and functional outcomes of TME with or without LLND in patients with rectal cancer.

Results Thirty-four included articles and 29 studies enrolled 11,606 patients. No difference in 5-year local recurrence (in every subgroup analysis including preoperative neoadjuvant chemoradiotherapy), 5-year distant and overall recurrence, 5-year overall survival and 5-year disease-free survival was found between LLND group and non LLND group. The analysis of post-operative functional outcomes reported hindered quality of life (urinary, evacuatory and sexual dysfunction) in LLND patients when compared to non LLND.

Conclusion Our publication does not demonstrate that TME with LLND has any oncological advantage when compared to TME alone, showing that with the advent of neoadjuvant therapy, the advantage of LLND is lost. In this review, the most important bias is the heterogeneous characteristics of patients, cancer staging, different neoadjuvant therapy, different radiotherapy techniques and fractionation used in different studies. Higher rate of functional post-operative complications does not support routinely use of LLND.
\end{abstract}

Keywords Rectal cancer $\cdot$ Total mesorectal excision $\cdot$ Lateral pelvic lymphadenectomy

Francesco Bagolini

bglfnc@unife.it

Alberto Arezzo

alberto.arezzo@unito.it

Vito D'Andrea

vito.dandrea@uniroma1.it

Georgi Popivanov

gerasimpopivanov@ rocketmail.com

Isaac Cheruiyot

isaacbmn@outlook.com

1 Dipartimento di Scienze Mediche, Università degli Studi di Ferrara, Ferrara, Italy

2 Cambridge Colorectal Unit - Addenbrooke's Hospital, Cambridge University Hospitals NHS Foundation Trust, Cambridge, UK
3 Department of Surgical Sciences, University of Torino, Corso Dogliotti 14, 10126 Torino, Italy

4 Department of Surgical Sciences, Sapienza University of Rome, Piazzale Aldo Moro 5, 00185 Rome, Italy

5 Department of Surgery and Biomedical Sciences, University of Perugia, 06121 Perugia, Italy

6 Department of General Surgery (S.D.S., G.I., E.Z., G.C.), University of Insubria, University Hospital of Varese, ASST Sette Laghi, Regione Lombardia, Italy

Department of Surgery, Military Medical Academy, ul. "Sv. Georgi Sofiyski" 3, 1606 Sofia, Bulgaria

8 Department of Human Anatomy, University of Nairobi, Nairobi, Kenya 


\section{Introduction}

Although commonly performed in urologic (1) and gynaecologic (2) surgery, the role of lateral lymph node dissection (LLND) is still a very controversial topic in rectal cancer treatment (3). This procedure, reported in Japan in the 1970s (4, 5), was standardized by Moriya at the end of the 1980s: "On the basis of the extent of lateral node spread, two types of lateral node dissection were performed, consisting of preservation of internal iliac vessels (conventional) and en-bloc excision of these vessels (extended)" (6).

Currently, total mesorectal excision (TME) remains the gold standard for surgical treatment of mid and low rectal cancer. In contrast, the place of LLND remains a matter of controversy between Eastern and Western surgical guidelines (7-12). The main conceptual difference is the fact that the lateral pelvic lymph nodes are considered as localized disease in Japanese clinical practice, whereas the West treats them as systemic disease (13-15). For this reason, in Japan, prophylactic LLND is always performed in patients with stage II/III lower rectal cancer, whereas in the West, chemoradiotherapy (CRT) is routinely performed, thus generally avoiding a more invasive surgical approach (16).

To date, seven systematic reviews and meta-analyses have provided the highest levels of evidence to support the role of LLND for rectal cancer (17-23). This new systematic review and meta-analysis aims to perform an updated analysis of the different types of treatments associated with prophylactic LLND vs. no-LLND (NLLND) in rectal cancer surgery.

\section{Methods}

We performed a systematic review adhering to AMSTAR 2 principles (24). A literature search was performed from two authors (R.C., F.B.) in PubMed, SCOPUS and WOS for publications up to 1 September 2020. The protocol for this study was registered on PROSPERO, a prospective international database for reviews under the registration number 42020186525 .

Inclusion criteria We considered RCTs (randomized control trial) and CCTs (clinical control trials) comparing patients with rectal cancer who underwent rectal resection and TME with versus without LLND.

Exclusion criteria Patients having surgery without TME.

The Preferred Reporting Items for Systematic Reviews and Meta-analyses (PRISMA) guidelines were followed (25)(ESM6). The keywords used for PubMed database research were: "extended lymphadenectomy," "pelvic lymphadenectomy," "lateral lymph-node dissection," "total mesorectal excision," "rectal resection," "rectal cancer," and their combinations. The search strategy performed on PubMed was the following: "extended lymphadenectomy"[All Fields] AND ("rectum" [MeSH Terms] OR rectum[All Fields]) "pelvic lymphadenectomy "[All Fields] AND (rectum[MeSH Terms] OR rectum[All Fields]) "lateral lymph-node dissection"[All Fields] AND (rectum[MeSH Terms] OR rectum[All Fields]).

We also manually searched the references of identified articles and relevant reviews and searched conference proceedings, theses and published abstracts on Google scholar. No language restriction was applied.

Outcomes The primary outcomes were the incidence of local recurrence and distant recurrence at 5 years. The secondary outcomes were the 5-year overall and disease-free survival and the incidence of urinary dysfunction (retention), urinary incontinence, evacuatory dysfunction and sexual dysfunction.

The assessment of methodological quality was performed independently by two authors (RC, CR). The risk of bias of randomized control trials (RCTs) was assessed using methods described in the Cochrane Handbook for Systematic Reviews of Interventions (26) and the ROBINS-I tool (27) for observational studies. In the ROBINS-I tool, risk of bias is assessed within specified domains, including bias due to confounding, bias in selection of participants into the study, bias in classification of interventions, bias due to deviations from intended interventions bias due to missing data, bias in measurement of outcomes, bias in selection of the reported result and overall bias. Bias assessments were tabulated with explanation. Disagreements were resolved via discussion between the investigators. Graphic representation of the results was produced using the Robvis online tool (28) (ESM4-5).

\section{Statistical analysis}

This meta-analysis was conducted using the Review Manager (RevMan version 5.3.5) computer program (Copenhagen: The Nordic Cochrane Centre, The Cochrane Collaboration, 2014).

The dichotomous outcomes were pooled with a randomeffects model with the Mantel-Haenszel method to estimate risk ratios (RRd) and their 95\% confidence intervals (29). Clinical heterogeneity was tested using $\tau 2$, Cochrane's Q and $\mathrm{I}^{2}$ statistics. We considered an $I^{2}$ value exceeding $50 \%$ to be indicative of heterogeneity (30).

We used a random-effect analysis model for the high clinical heterogeneity and statistically significant higher $\mathrm{chi}^{2}$ value and $I^{2}(31)$. In all remaining circumstances, we used the random-effects model.

The following subgroup analyses were performed to reduce the heterogeneity:

- LLND vs. NLLND

- LLND vs. NLLND and adjuvant therapy 
Table 1 Included studies

\begin{tabular}{|c|c|c|c|c|c|c|c|c|}
\hline & $\begin{array}{l}\text { Author and year } \\
\text { of publication }\end{array}$ & Nation & Type of study & $\begin{array}{l}\text { Time of } \\
\text { enrolment }\end{array}$ & $\begin{array}{l}\text { Location } \\
\text { of cancer }\end{array}$ & $\begin{array}{l}\text { Clinical AJCC } \\
\text { staging }\end{array}$ & $\begin{array}{l}\text { Patients } \\
\text { included }\end{array}$ & $\begin{array}{l}\text { Type of rectal } \\
\text { resection }\end{array}$ \\
\hline 1 & Tsukamoto 2020 (40) & Japan & $\mathrm{RCT}$ & $2003-2010$ & Rectum L & II/III & 701 & NR \\
\hline 2 & $\begin{array}{l}\text { Oki } \\
2019 \text { (46) }\end{array}$ & Japan & RCT & $2006-2009$ & Rectum & $\mathrm{I} / \mathrm{II} / \mathrm{III}$ & 445 & $\begin{array}{l}\text { RAR } \\
\text { APR } \\
\text { HP } \\
\text { Others }\end{array}$ \\
\hline 3 & Nishizaki 2019 (47) & Japan & $\begin{array}{l}\text { Retrospective } \\
\text { CCT }\end{array}$ & NR & Rectum & NR & 155 & NR \\
\hline 4 & $\begin{array}{l}\text { Ogura } \\
2019(48)\end{array}$ & $\begin{array}{l}\text { Australia//Korea/ } \\
\text { Netherlands/Japan/ } \\
\text { UK/USA }\end{array}$ & $\begin{array}{l}\text { Prospective } \\
\text { CCT }\end{array}$ & $2009-2013$ & Rectum L & NR & 968 & $\begin{array}{l}\text { RAR } \\
\text { APR } \\
\text { PE } \\
\text { Others }\end{array}$ \\
\hline 5 & Matsuda 2018 (49) & Japan & Retrospective CCT & $2005-2016$ & Rectum & $\mathrm{I} / \mathrm{II} / \mathrm{III}$ & 45 & $\begin{array}{l}\text { RAR } \\
\text { APR } \\
\text { HP } \\
\text { Others }\end{array}$ \\
\hline 6 & $\begin{array}{l}\text { Park } \\
2018 \text { (50) }\end{array}$ & Korea & Retrospective CCT & 2011-2016 & Rectum L & II/III & 361 & $\begin{array}{l}\text { RAR } \\
\text { APR } \\
\text { HP }\end{array}$ \\
\hline 7 & $\begin{array}{l}\text { Ito } \\
2018 \text { (43) }\end{array}$ & Japan & RCT & $2003-2010$ & Rectum & NR & 701 & NR \\
\hline 8 & $\begin{array}{l}\text { Dev } \\
2017(51)\end{array}$ & India & RCT & NR & Rectum L & II/III & 240 & NR \\
\hline 9 & Georgiu 2017 (17) & UK & $\begin{array}{l}\text { Retrospective } \\
\text { CCT }\end{array}$ & $2006-2009$ & Rectum & NR & 38 & $\mathrm{PE}$ \\
\hline 10 & Ishihara 2017 (52) & Japan & $\begin{array}{l}\text { Retrospective } \\
\text { CCT }\end{array}$ & $2003-2015$ & Rectum L & NR & 222 & $\begin{array}{l}\text { RAR } \\
\text { APR } \\
\text { HP } \\
\text { PE } \\
\text { Others }\end{array}$ \\
\hline 11 & $\begin{array}{l}\text { Fujita } \\
2017 \text { (41) }\end{array}$ & Japan & $\mathrm{RCT}$ & $2003-2010$ & Rectum L & II/III & 701 & RAR \\
\hline 12 & Tamura 2017 (53) & Japan & $\begin{array}{l}\text { Retrospective } \\
\text { CCT }\end{array}$ & $2000-2015$ & Rectum L & IV & 50 & NR \\
\hline 13 & Kim 2017 (54) & Korea & $\begin{array}{l}\text { Retrospective } \\
\text { CCT }\end{array}$ & NR & Rectum L & NR & 377 & $\begin{array}{l}\text { RAR } \\
\text { APR }\end{array}$ \\
\hline 14 & Ogura 2017 (48) & Japan & $\begin{array}{l}\text { Retrospective } \\
\text { CCT }\end{array}$ & $2005-2014$ & Rectum L & II/III & 363 & $\begin{array}{l}\text { RAR } \\
\text { APR } \\
\text { HP } \\
\text { Others }\end{array}$ \\
\hline 15 & $\begin{array}{l}\text { Saito } \\
2016 \text { (44) }\end{array}$ & Japan & RCT & $2003-2010$ & Rectum & II/III & 701 & NR \\
\hline 16 & $\begin{array}{l}\text { Ozawa } \\
2016(55)\end{array}$ & Japan & $\begin{array}{l}\text { Retrospective } \\
\text { CCT }\end{array}$ & $1995-2004$ & Rectum L & II/III & 998 & $\begin{array}{l}\text { RAR } \\
\text { APR } \\
\text { Others }\end{array}$ \\
\hline 17 & $\begin{array}{l}\text { Akiyoshi } \\
2019(56)\end{array}$ & Japan & $\begin{array}{l}\text { Retrospective } \\
\text { CCT }\end{array}$ & $2004-2010$ & Rectum L & II-III & 127 & $\begin{array}{l}\text { RAR } \\
\text { APR } \\
\text { HP } \\
\text { Others }\end{array}$ \\
\hline 18 & $\begin{array}{l}\text { Fujita } \\
2013 \text { (42) }\end{array}$ & Japan & $\mathrm{RCT}$ & $2003-2010$ & Rectum L & II/III & 701 & RAR \\
\hline 19 & $\begin{array}{l}\text { Akasu } \\
2009 \text { (79) }\end{array}$ & Japan & $\begin{array}{l}\text { Retrospective } \\
\text { CCT }\end{array}$ & $1992-2006$ & Rectum L & NR & 69 & NR \\
\hline 20 & Kusters 2009 (57) & Netherlands/ Japan & $\begin{array}{l}\text { Prospective } \\
\text { CCT }\end{array}$ & $1993-2002$ & Rectum L & $\mathrm{I} / \mathrm{II} / \mathrm{III}$ & 1.079 & $\begin{array}{l}\text { RAR } \\
\text { APR } \\
\text { HP } \\
\text { PE }\end{array}$ \\
\hline 21 & Kobayashi 2009 (58) & Japan & $\begin{array}{l}\text { Retrospective } \\
\text { CCT }\end{array}$ & 1991-1998 & Rectum L & $\mathrm{I} / \mathrm{II} / \mathrm{III}$ & 1.272 & NR \\
\hline
\end{tabular}


Table 1 (continued)

\begin{tabular}{|c|c|c|c|c|c|c|c|c|}
\hline & $\begin{array}{l}\text { Author and year } \\
\text { of publication }\end{array}$ & Nation & Type of study & $\begin{array}{l}\text { Time of } \\
\text { enrolment }\end{array}$ & $\begin{array}{l}\text { Location } \\
\text { of cancer }\end{array}$ & $\begin{array}{l}\text { Clinical AJCC } \\
\text { staging }\end{array}$ & $\begin{array}{l}\text { Patients } \\
\text { included }\end{array}$ & $\begin{array}{l}\text { Type of rectal } \\
\text { resection }\end{array}$ \\
\hline 22 & Shiozawa 2007 (59) & Japan & $\begin{array}{l}\text { Retrospective } \\
\text { CCT }\end{array}$ & $1990-2000$ & Rectum L & NR & 169 & NR \\
\hline 23 & Kim 2007 (60) & Korea & $\begin{array}{l}\text { Retrospective } \\
\text { CCT }\end{array}$ & $1995-2000$ & Rectum L & III & 290 & $\begin{array}{l}\text { RAR } \\
\text { APR }\end{array}$ \\
\hline 24 & $\begin{array}{l}\text { Yano } \\
2007(61)\end{array}$ & Japan & $\begin{array}{l}\text { Prospective } \\
\text { CCT }\end{array}$ & $1995-2003$ & Rectum & I/II/III/IV & 109 & $\begin{array}{l}\text { RAR } \\
\text { APR } \\
\text { HP }\end{array}$ \\
\hline 25 & Куо 2006 (62) & Japan & $\begin{array}{l}\text { Prospective } \\
\text { CCT }\end{array}$ & $1998-2000$ & Rectum & I/II/III/IV & 37 & $\begin{array}{l}\text { RAR } \\
\text { APR } \\
\text { HP }\end{array}$ \\
\hline 26 & Col 2005 (63) & Turkey & $\begin{array}{l}\text { Retrospective } \\
\text { CCT }\end{array}$ & $1997-2000$ & Rectum & NR & 170 & $\begin{array}{l}\text { RAR } \\
\text { APR }\end{array}$ \\
\hline 27 & Hasdemir 2005 (64) & Turkey & $\begin{array}{l}\text { Retrospective } \\
\text { CCT }\end{array}$ & NR & Rectum U/M/L & $\mathrm{I} / \mathrm{II} / \mathrm{III}$ & 170 & $\begin{array}{l}\text { RAR } \\
\text { APR }\end{array}$ \\
\hline 28 & Matsuoka 2005 (65) & Japan & $\begin{array}{l}\text { Prospective } \\
\text { CCT }\end{array}$ & $1998-2003$ & Rectum & NR & 57 & RAR \\
\hline 29 & Fujita 2003 (66) & Japan & $\begin{array}{l}\text { Retrospective } \\
\text { CCT }\end{array}$ & $1985-1998$ & $\begin{array}{l}\text { Rectum L } \\
\text { Anal Canal }\end{array}$ & II/III & 246 & $\begin{array}{l}\text { RAR } \\
\text { APR }\end{array}$ \\
\hline 30 & Maeda 2003 (67) & Japan & $\begin{array}{l}\text { Prospective } \\
\text { CCT }\end{array}$ & 1988-1996 & Rectum U/L & NR & 77 & $\begin{array}{l}\text { RAR } \\
\text { APR }\end{array}$ \\
\hline 31 & Watanabe 2002 (7) & Japan & $\begin{array}{l}\text { Retrospective } \\
\text { CCT }\end{array}$ & $1985-1995$ & Rectum L & NR & 115 & $\begin{array}{l}\text { RAR } \\
\text { APR } \\
\text { HP } \\
\text { PE }\end{array}$ \\
\hline 32 & Nagawa 2001 (45) & Japan & RCT & 1993-1995 & Rectum L & NR & 45 & $\begin{array}{l}\text { RAR } \\
\text { APR }\end{array}$ \\
\hline 33 & $\begin{array}{l}\text { Suzuki } \\
1995 \text { (68) }\end{array}$ & Japan & $\begin{array}{l}\text { Retrospective } \\
\text { CCT }\end{array}$ & $1963-1990$ & Rectum U/L & NR & 192 & $\begin{array}{l}\text { RAR } \\
\text { APR } \\
\text { Others }\end{array}$ \\
\hline 34 & Moreira 1994 (69) & Japan & $\begin{array}{l}\text { Retrospective } \\
\text { CCT }\end{array}$ & 1981-1991 & Rectum & NR & 178 & NR \\
\hline
\end{tabular}

$A P R$ abdominoperineal resection, $I R$ intersphincteric resection, $L L N D$ lateral lymph node dissection, Non- $L L N D$ non-lateral lymph node dissection, $P E$ pelvic exenteration, $R A R$ rectal anterior resection, $U$ upper, $M$ Mid, $L$ lower, $M E$ mesorectal excision

- $\quad$ LLND and adjuvant therapy vs. NLLND and adjuvant therapy

- LLND vs nCRT and NLLND

- nCRT and LLND vs nCRT and NLLND

\section{Results}

The PRISMA flow diagram for the systematic review is presented in SDC 1 (ESM1). The initial search yielded 2833 potentially relevant articles. After the removal of duplicates, 1767 studies underwent screening of titles/abstracts for relevance and assessment for eligibility; 1724 further articles were eventually excluded leaving 43 studies for analysis of the full text. Of these, nine studies, included in the other systematic review (17-23), were successively excluded (SDC 2)(ESM2) (5, 32-39). The remaining 34 articles and 29 studies (11.606 patients: 5161 underwent LLND and 6445 NLLND) were included in this systematic review and meta-analysis. One study (Tsukamoto 2020) (40) overlapped with a previous study (Fujita 2017) (41). In effect, the study of Tsukamoto et al. is the result of a long-term follow-up of the Japan Clinical Oncology Group (JCOG) 0212 (ClinicalTrials.gov NCT00190541) published previously from Fujita et al. in 2017. The other studies included as RCT (40-44) are all based on the same trial (JCOG0212) and therefore represent the same group of patients. The studies of Nagawa 2001 (45) and Watanabe 2002 (7) are both from the same single institution with overlapped years.

\section{Characteristics of the studies}

The 28 included studies were published between 1994 and 2020; patients were enrolled between 1985 and 2016 (Table 1). In all studies, the cancer was located at the rectum, 


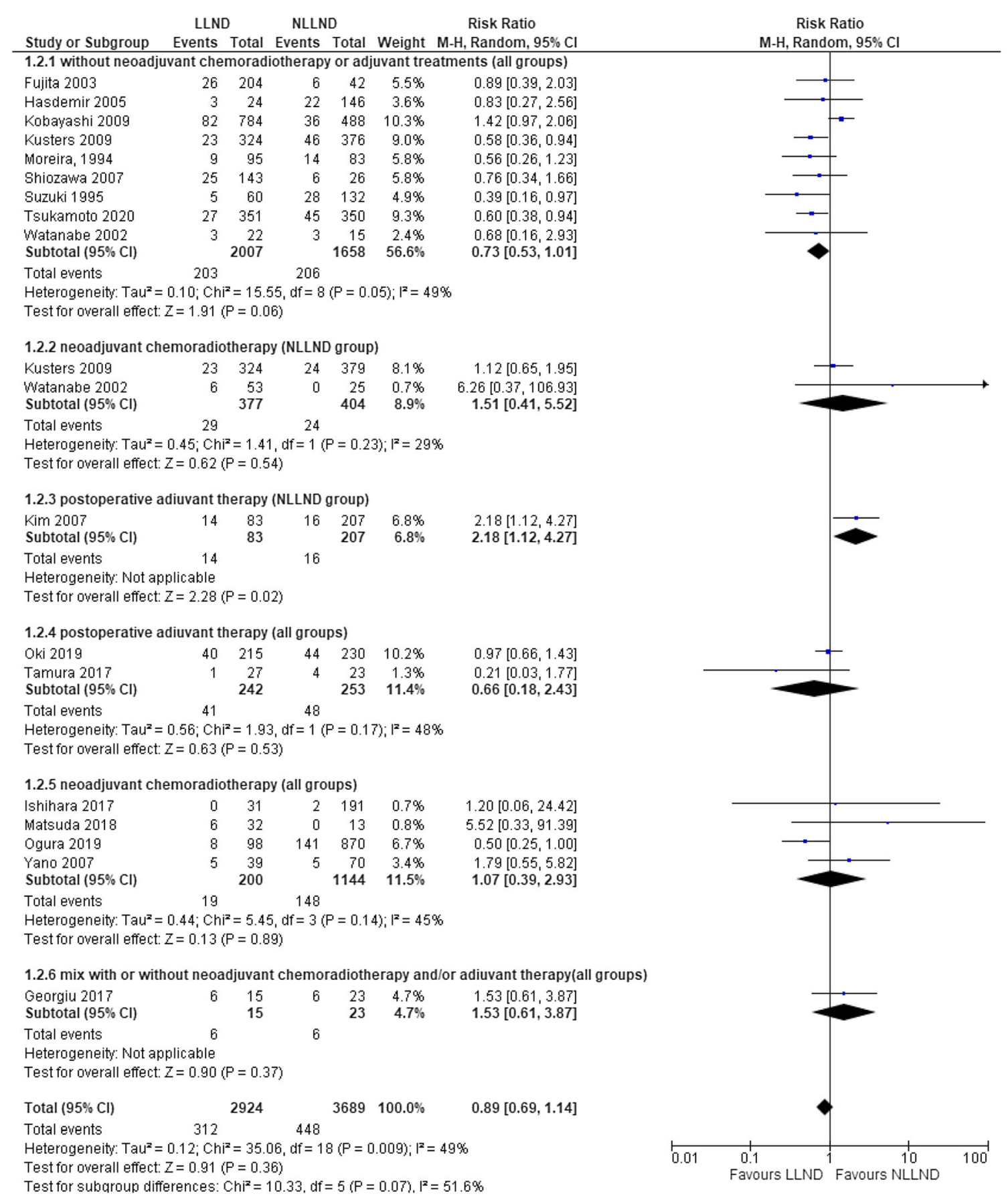

Fig. 1 Forest plot, 5-year local recurrence

except one that also included patients with anal cancer (66). The level of the cancer was reported in 22 studies. In 18 studies $(85.7 \% \%)$, the tumour was located in the lower rectum. A small proportion of studies included patients with upper rectal cancer $(14.3 \%)(64,67,68)$.

The clinical AJCC staging was reported in 17 studies (50\%): II/III stages (9 studies), I/II/III stages (4 studies), I/II/ III/IV stages (2 studies), III stage (1 study) and IV stage (1 study). A TME was performed in all patients, and the type of rectal resection was reported in 24 studies (70.6\%): anterior resection (23 studies), abdominoperineal resection (20 studies), Hartmann's procedure (10 studies) and pelvic exenteration (3 studies).

Risk of bias Seven domains for the potential risk of bias of included RCTs using methods described in the Cochrane Handbook for Systematic Reviews of Interventions were analysed (26). All studies were rated as unclear risk of random 


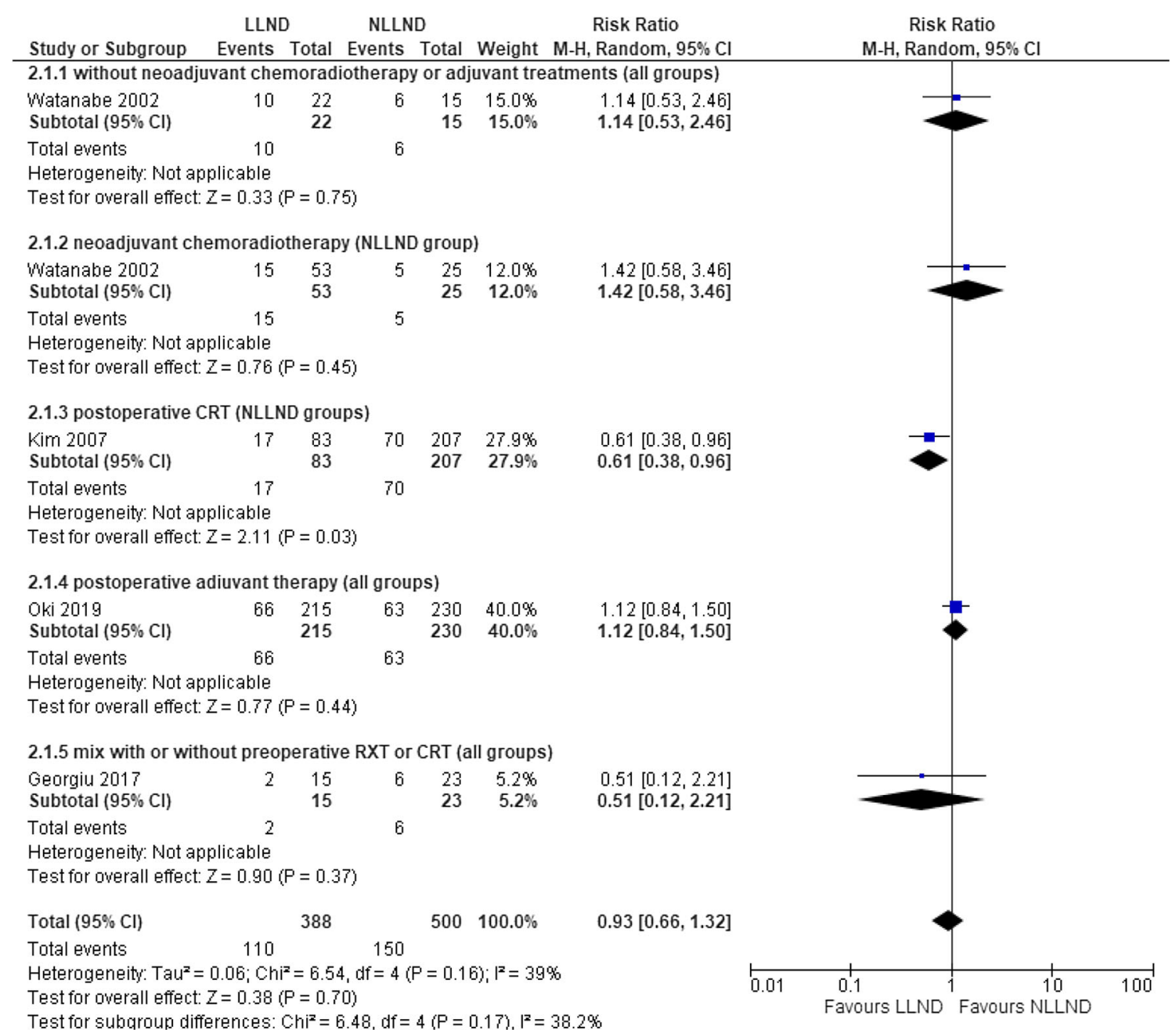

Fig. 2 Forest plot 5-year distant recurrence

sequence generation (selection bias) and five studies for allocation concealment (selection bias). Blinding of participants and personnel and incomplete outcome data were rated as high risk in all included studies. Five studies were rated as low risk of selection bias for selective reporting (reporting bias) and other bias. The ROBINS-I tool was used to evaluate the quality of the comparative studies.

\section{Primary outcomes}

Local recurrence at 5 years Seventeen studies (7, 17, 42, 45, $46,48,49,52,53,57-61,64,66,68,69)$ reported local recurrence in 6613 patients (2.924 LLND and 3689 NLLND). The incidence of local recurrence was not statistically different between the overall LLND group $(10.7 \%, 312 / 2.924)$ and the overall NLLND group $(12.1 \%, 448 / 3.689)$ (RR 0.89, $95 \%$ CI 0.69 to $1.14 ; I^{2}=49 \%, P=0.36$ ) (Fig. 1 ).

In the subgroup analysis of patients who underwent LLND vs NLLND without (Fig. 1 (1.2.1)) or with adjuvant therapy (Fig. 1 (1.2.4)), there was no statistical difference between local recurrence rates in LLND (10.1\%) and NLLND
(12.4\%) group [respectively RR 0.73 (95\% CI 0.53 to 1.01 ) and RR 0.66 (95\% CI 0.18 to 2.43 )].

In the patients who underwent LLND vs NLLND with neoadjuvant CRT, local recurrence rate was the same in LLND and NLLND (RR 1.51, 95\% CI 0.41-5.52) (Fig. 1 $(1.2 .2))$

In all groups that underwent neoadjuvant CRT, there was not a significant difference in local recurrence rate in LLND group (RR 1.07, 95\% CI 0.39-2.93) (Fig. 1 (1.2.5)).

Distant recurrence at 5 years Four studies (7, 17, 45, 46, 60), including 888 patients (388 LLND and 500 NLLND), reported the rate of distant recurrence.

There was no significant difference in distant recurrence rate between the LLND group $(28.6 \%, 110 / 388)$ and the NLLND group $(30 \%, 150 / 500)$ (RR $0.93,95 \%$ CI 0.66 to $1.32 ; I^{2}=39 \%$ ) (Fig. 2). In the subgroup analysis, the results did not show a statistically significant advantage for any group of patients, despite the better results in NLLND with neoadjuvant CRT compared with LLND alone (RR 1.42, 95\% CI 0.58-3.46) (Fig. 2 (2.1.2)). 


\section{Secondary outcomes}

Overall 5-year survival Ten studies $(41,45,46,52,53,55$, 58-60, 64, 69), including 5132 patients (2560 LLND and 2572 NLLND), reported the rate of this outcome. The overall survival at 5 years was not statistically different between the LLND group (76.6\%) and the NLLND group (74.6\%), (RR $0.90,95 \%$ CI 0.79 to $1.01 ; I^{2}=17 \%$ ) (Fig. 3).

Disease-free 5-year survival Six studies $(41,45-47,59,60,64)$, including 1922 patients (913 LLND and 1054 NLLND), reported the rate of this outcome. There was no statistical difference in terms of disease-free survival at 5 years when comparing the LLND group (67.9\%) to the NLLND group (65\%), (RR $0.87,95 \%$ CI 0.75 to $1.01 ; I^{2}=24 \%$ ) (Fig. 4).

Urinary retention Seven studies $(43,45,46,50,62,63,67)$, including 1718 patients (665 LLND and 1053 NLLND), reported urinary dysfunction. The incidence of urinary retention was significantly higher in the LLND patients (37\%) if compared to the NLLND group (24.4\%) (RR 1.88, 95\% CI 1.11 to $\left.3.19 ; I^{2}=68 \%\right)$ (Fig. 5).

Urinary incontinence Four studies $(62,63,65,67)$, including 341 patients (119 LLND and 222 NLLND), reported urinary incontinence. The incidence of urinary incontinence was similar between the LLND group (23.5\%) and the NLLND group (27.4\%) (RR 1.35, 95\% CI 0.94 to $\left.1.92 ; I^{2}=0 \%\right)$ (Fig. 6 ).

Sexual dysfunction Four studies (44, 45, 62, 67), including 140 patients (27 LLND and 57 NLLND), reported sexual dysfunction. The incidence of sexual dysfunction was similar between the LLND group (61.7\%) and the NLLND group (47\%) (RR $1.87,95 \%$ CI 0.91 to $3.84 ; I^{2}=65 \%$ ) (Fig. 7 ).

Evacuatory dysfunction Two studies $(45,65)$, including 84 patients (27 LLND and 57 NLLND), reported evacuatory

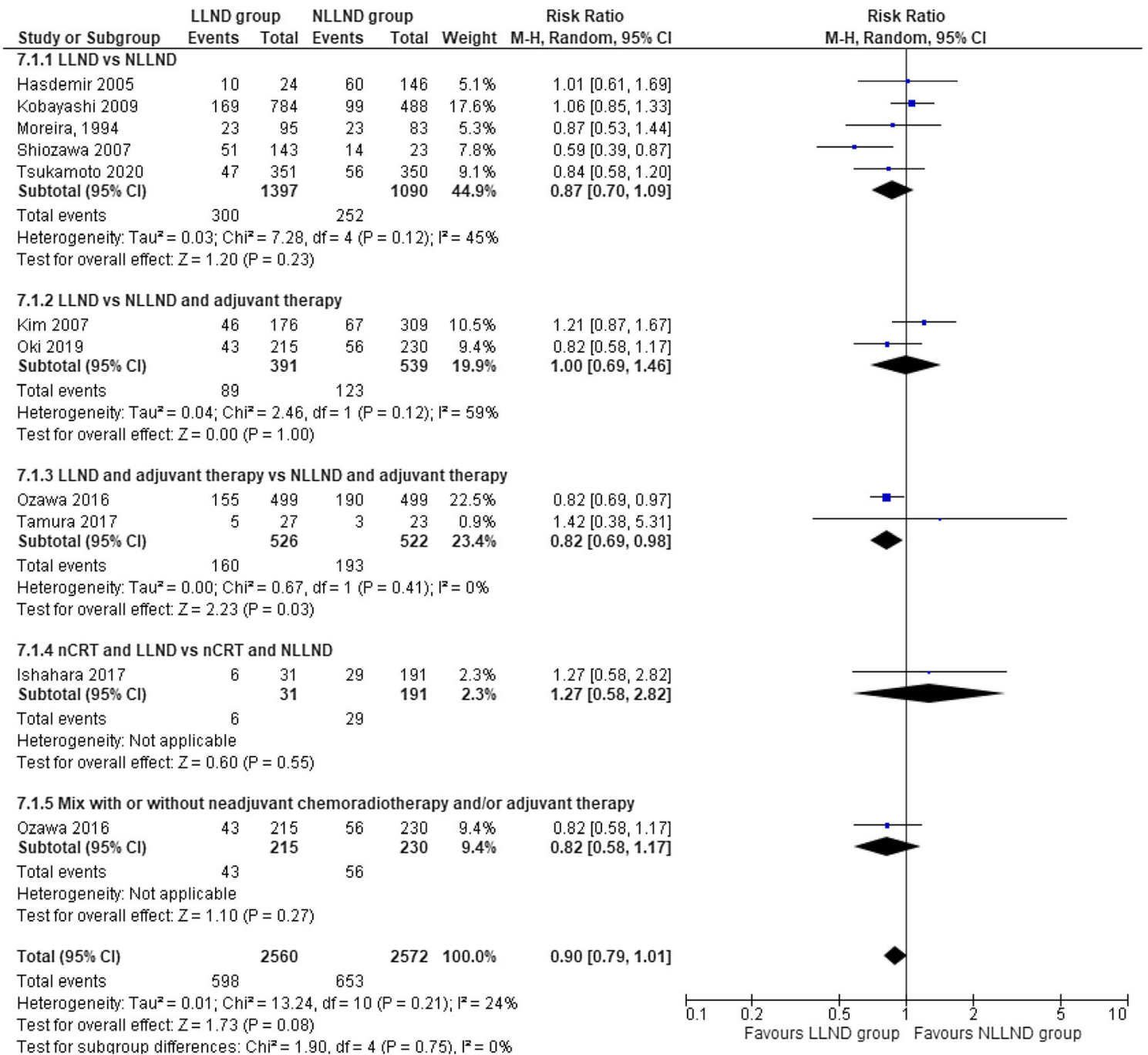

Fig. 3 Forest plot overall survival at 5 years 


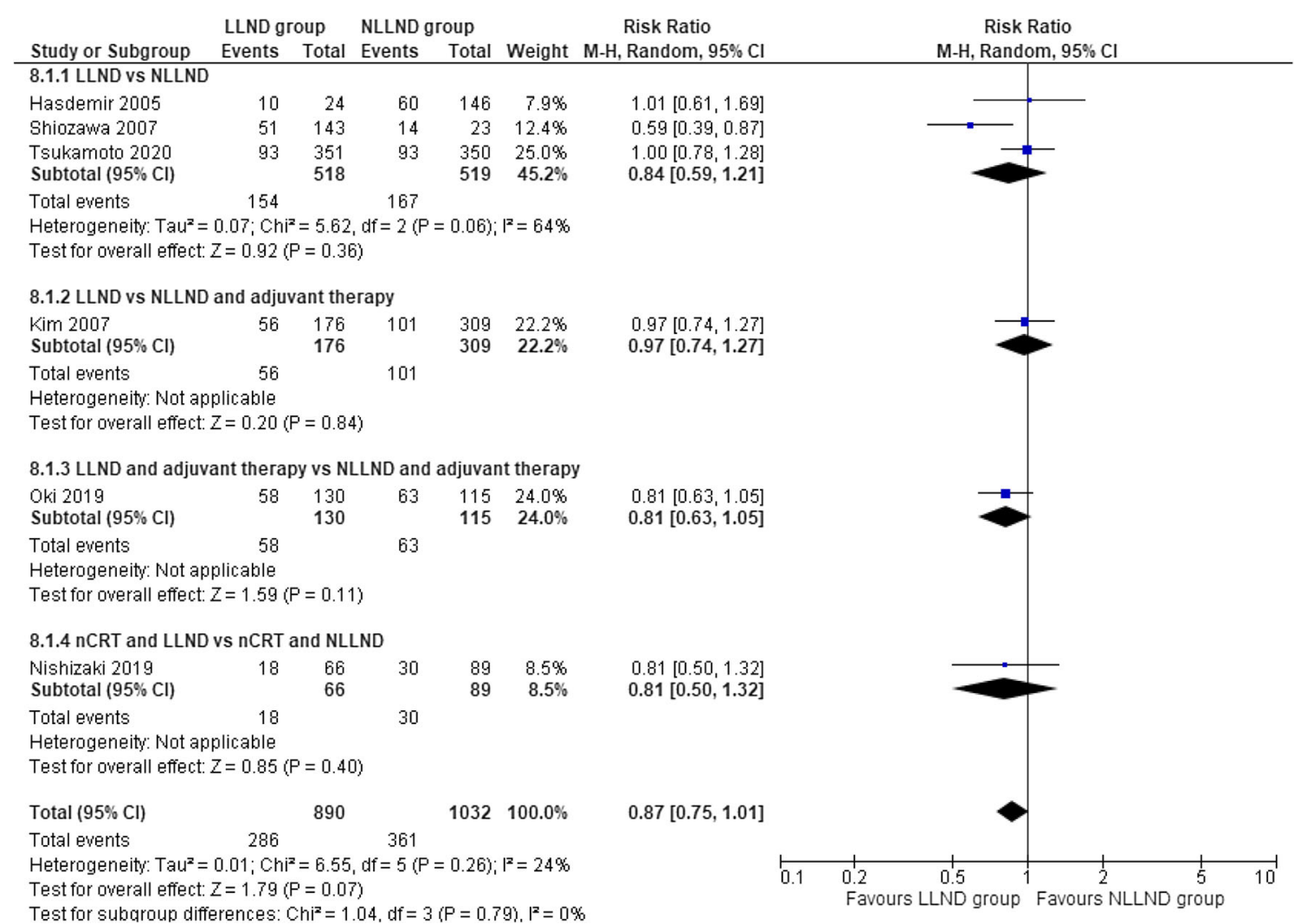

Fig. 4 Forest plot disease-free survival at 5 years

dysfunction. The incidence of evacuatory dysfunction was similar between the LLND group (62.9\%) and the NLLND group (43.9\%) (RR $1.57,95 \%$ CI 1.00 to $2.47 ; I^{2}=15 \%$ ) (SDC 3)(ESM3).

\section{Discussion}

Rectal cancer represents the third leading cause of death worldwide with a steadily increasing incidence $(70,71)$. The concept of TME, introduced by Heald, has revolutionized the treatment by reducing the local recurrence rates from up to $40 \%$ to $4-8 \%(15,71)$. TME does not include the removal of the lateral pelvic lymph nodes but only those found within the mesorectal fascia and along the course of the mesenteric vessels. The efficacy of the excision of the pelvic lateral lymph nodes is still a controversial topic $(72,73)$.

The lymphatic drainage of the rectum, especially for the most distal/lower rectum, through the submucosal plexus, drains in three trunks: the upper branch, which flows into the lymphatic channels of the lower mesenteric vein; the middle branch, draining to the lymph nodes surrounding the internal, external and common iliac vessels; the lower branch draining to the inguinal lymph nodes (15) (Table 2; Fig. 8). These lateral regional lymphatic areas outside of the mesorectum are classified into six regions near the following arteries: the internal

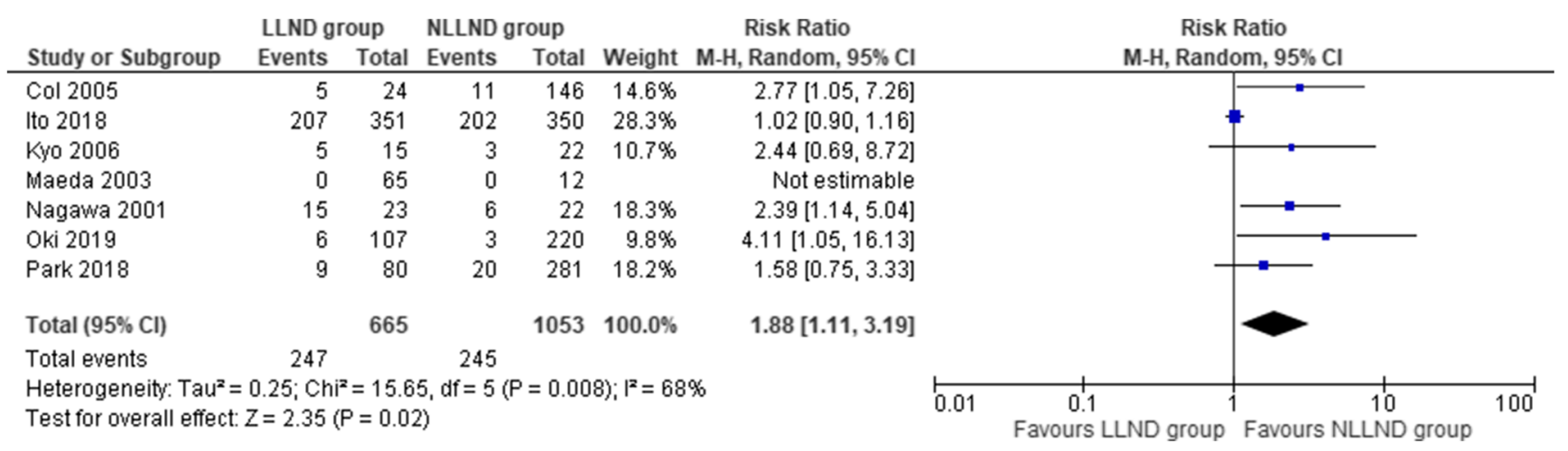

Fig. 5 Forest plot urinary dysfunction (retention) 


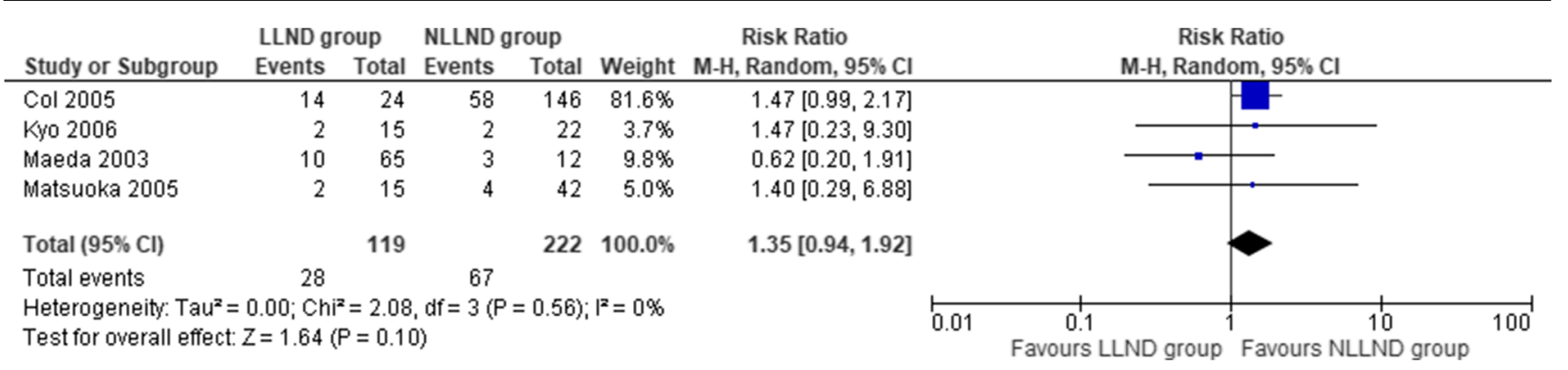

Fig. 6 Forest plot urinary incontinence

pudendal (outside of the pelvic plexus), the internal iliac (proximal to the superior vesical artery), the common iliac, the external iliac, the obturator and the presacral regions. Among these regions, the internal iliac artery and obturator regions have the highest rate of nodal involvement (22-61\%) and are called the 'vulnerable field' $(13,14)$.

The different approaches to the LLND between the East and West stems from the concept that pelvic lateral lymph nodes are considered regional according to Japanese authors and staging systems. The Western world, with the latest AJCC guidelines (AJCC $8^{\text {th }}$ edition), confirms pelvic lateral lymph node stations as remote stations. This is mainly debated in the case of stage II and III low rectal cancer. The involvement of lymph node stations in the iliac and obturator regions varies from 10.6 to $25.5 \%$ (15) stage II and III rectal cancer below the peritoneal reflection. More specifically, pelvic extra-regional lymph node involvement is reported in $5.4 \%$ of $\mathrm{T} 1$ cases, $8.2 \%$ for $\mathrm{T} 2$, $16.5 \%$ for $\mathrm{T} 3$ and $37.2 \%$ for T4 (58). For this reason, Japanese surgeons suggest performing TME with bilateral pelvic lymphadenectomy without neoadjuvant treatment, as they expect that the risk of intrapelvic recurrence decreases by $50 \%$, and 5-year survival improves by 8 to $9 \%(7,8)$.

On the contrary, surgeons of the Western world generally treat rectal cancer with a classical TME and often considering neoadjuvant CRT(74), preserving LLND for patients with clinically suspected lateral pelvic lymph node metastasis (9-11).

The comparison between LLND versus CRT for lateral pelvic lymph nodes mainly concerns the rate of local pelvic recurrence. The only RCT comparing these two surgical techniques is JCOGO212 (41), which compared TME vs. TME and lateral pelvic lymphadenectomy in patients who had no lateral pelvic lymphadenopathy before surgery. The rate of local recurrence decreased from $12.6 \%$ in cases of TME alone to $7.4 \%$ when TME was associated with lateral lymphadenectomy. A limitation of this study was the choice of not performing preoperative CRT before TME, even when it would have been indicated according to Western guidelines $(12,74)$. Long-term followup of JCOGO212 confirms the non-inferiority of TME alone compared to TME with pelvic lymphadenectomy in patients without clinically identifiable pelvic lymph node involvement. The study concludes that pelvic lateral lymphadenectomy should only be performed in patients with radiological evidence of lymph node involvement.

Other studies (54) confirm that the risk of pelvic recurrence rises to $19.5 \%$ in patients with lateral pelvic lymph nodes of a size more than $7 \mathrm{~mm}$ after neoadjuvant therapy. On the other hand, there is little evidence on the true efficacy of bilateral pelvic lymphadenectomy for low rectum carcinomas without clinical evidence of bilateral pelvic lymphadenopathy (41). Although TME alone should not be considered inferior to TME with lateral lymphadenectomy, surgery extended to lateral pelvic lymph nodes reduces the risk of pelvic recurrence, especially in radiologically positive cases.

The main point of the discussion remains the risk of lateral pelvic lymph node metastases even after neoadjuvant CRT. The literature (72) reports a high percentage (up to $30-40 \%$ ) of pelvic lymph node involvement even after neoadjuvant CRT.

The results from the present analysis confirm that the more radical and invasive surgical approach does not appear to be the safest and optimal way to treat these patients. The comparison between LLND and NLLND groups showed no

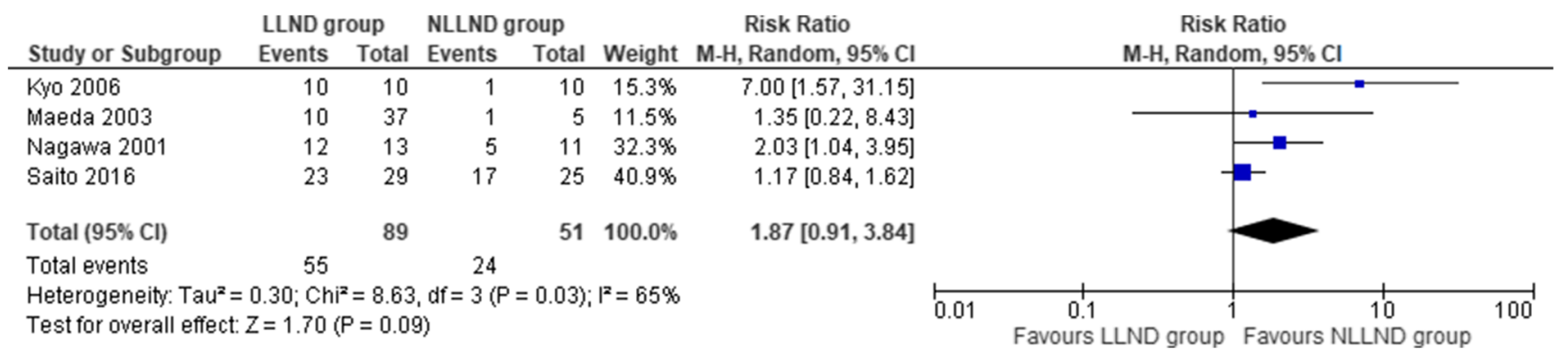

Fig. 7 Forest plot sexual dysfunction 
Table 2 Lymphatic drainage of the rectum

\begin{tabular}{lll}
\hline Lymphatic drainage & Lymph node group & Tributary Veins \\
\hline Upper branch & Rectosigmoid nodes & Lower mesenteric vein \\
Middle branch & Iliac nodes & Common iliac vein \\
& Sacral nodes & Internal Iliac vein \\
& & External Iliac vein \\
Lower branch & Inguinal nodes & Epigastric vein \\
& Obturatory nodes & Pudendal vein \\
& External Iliac nodes & External iliac vein \\
& Pelvic nodes & \\
\hline
\end{tabular}

difference in the rate of local recurrence and distant metastases. The central role in the prevention of local recurrences seems to be the use of neoadjuvant CRT, as the only group with statistically improved results was the non-LLND with neoadjuvant CRT when compared to LLND only. Regarding overall survival, the cumulative analysis also revealed a lack of any advantage of LLND, but the subgroup analysis did show improved overall survival in the group with LLND plus neoadjuvant CRT.

The main concern for the more invasive surgical approach of LLND is additional complications. It is recognized that higher occurrence of urinary, defecatory and sexual dysfunctions is found after LLND $(3,75)$, despite the introduction of nerve-sparing techniques. In the present analysis, the incidence of urinary retention and incontinence and sexual dysfunctions was directly compared in patients with and without LLND. The only statistically significant difference was the higher incidence of urinary retention in patients undergoing LLND. Another possible confounding factor is the fact that the comparison in most cases was carried out on patients without CRT, which is a procedure also burdened with similar and potentially additional, functional complications. More

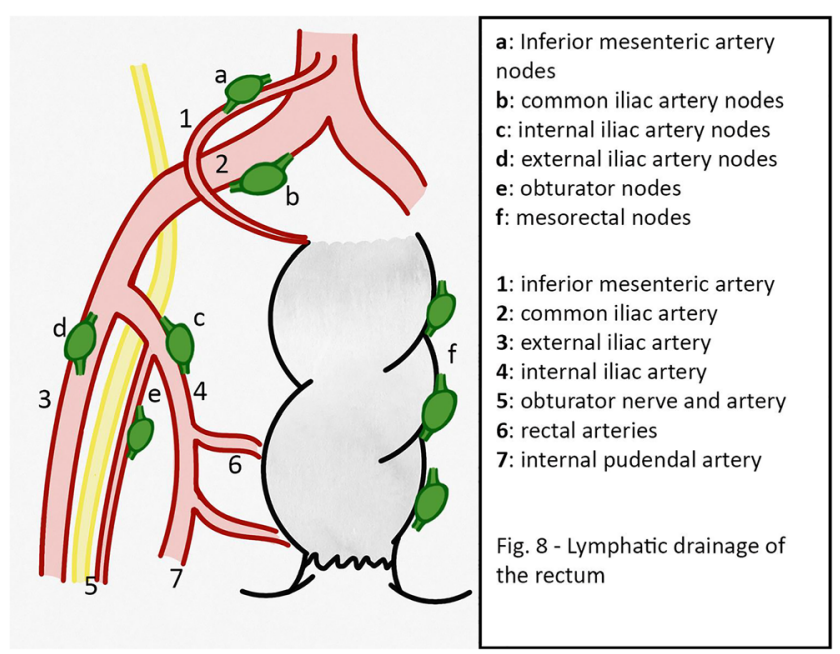

Fig. 8 Lymphatic drainage of the rectum targeted studies are needed to assess the safety and quality of life following LLND surgery.

An important limitation of the present analysis is the possible bias introduced by the high heterogeneity of the clinical and oncological status of the included patients. Furthermore, our analysis could be expanded and completed by examining other data, such as the number of harvested lymph nodes, additional lymph node metastases detected in the LLND group and differences in functional outcomes between minimally invasive surgeries versus open resections.

\section{Conclusion}

Our results suggest that TME with LLND does not offer an oncological advantage over TME without LLND. The advantage of LLND in the pre-neoadjuvant CRT era is lost after the implementation of neoadjuvant CRT. The addition of adjuvant CRT to LLND appears to contribute towards better survival and diminishes the rate of local recurrences. Whilst incurring in heterogeneity of data analysing currently available literature, the evidence would suggest that there is no place for routine LLND in the management of rectal cancer.

These findings reiterate the importance of careful selection of patients for LLND through an improved definition of pathological lymph nodes. Improved imaging techniques to accurately define a reliable cut-off size and describe radiological abnormalities that accurately predict involvement of pelvic lymph nodes are needed. Further studies, preferably prospective, that focus on survival and its association with surgical technique are needed to establish an evidence-based cut-off, which would aid in identifying precise indications for LLND.

Supplementary Information The online version contains supplementary material available at https://doi.org/10.1007/s00384-021-03946-2.

Funding Open access funding provided by Università degli Studi di Ferrara within the CRUI-CARE Agreement.

\section{Declarations}

Conflict of interest The authors declare no competing interests.

Open Access This article is licensed under a Creative Commons Attribution 4.0 International License, which permits use, sharing, adaptation, distribution and reproduction in any medium or format, as long as you give appropriate credit to the original author(s) and the source, provide a link to the Creative Commons licence, and indicate if changes were made. The images or other third party material in this article are included in the article's Creative Commons licence, unless indicated otherwise in a credit line to the material. If material is not included in the article's Creative Commons licence and your intended use is not permitted by statutory regulation or exceeds the permitted use, you will need to obtain permission directly from the copyright holder. To view a copy of this licence, visit http://creativecommons.org/licenses/by/4.0/. 


\section{References}

1. Silberstein JL, Vickers AJ, Power NE, Parra RO, Coleman JA, Pinochet R, Touijer KA, Scardino PT, Eastham JA, Laudone VP (2012) Pelvic lymph node dissection for patients with elevated risk of lymph node invasion during radical prostatectomy: Comparison of open, laparoscopic and robot-assisted procedures. J Endourol 26(6):748-753

2. Wisner KPA, Ahmad S, Holloway RW (2017) Indications and techniques for robotic pelvic and para-aortic lymphadenectomy with sentinel lymph node mapping in gynecologic oncology. Bailliere Tindall Ltd:83-93

3. Koch M, Kienle P, Antolovic D, Büchler MW, Weitz J (2005) Is the lateral lymph node compartment relevant? Recent Results Cancer Res:40-45

4. Hojo K, Koyama Y, Moriya Y (1982) Lymphatic spread and its prognostic value in patients with rectal cancer. Am J Surg 144(3): 350-354

5. Koyama Y, Moriya Y, Hojo K (1984) Effects of Extended Systematic Lymphadenectomy for Adenocarcinoma of the Rectum-Significant Improvement of Survival Rate and Decrease of Local Recurrence- - Jpn J Clin Oncol 14(4):623-632

6. Moriya Y, Hojo K, Sawada T, Koyama Y (1989) Significance of lateral node dissection for advanced rectal carcinoma at or below the peritoneal reflection. Dis Colon Rectum 32(4):307-315

7. Watanabe T, Tsurita G, Muto T, Sawada T, Sunouchi K, Higuchi Y, Komuro Y, Kanazawa T, Iijima T, Miyaki M, Nagawa H (2002) Extended lymphadenectomy and preoperative radiotherapy for lower rectal cancers. Surgery. 132(1):27-33

8. Sugihara K, Kobayashi H, Kato T, Mori T, Mochizuki H, Kameoka S, Shirouzu K, Muto T (2006) Indication and benefit of pelvic sidewall dissection for rectal cancer. Dis Colon Rectum 49(11): $1663-1672$

9. Nelson H, Petrelli N, Carlin A, Couture J, Fleshman J, Guillem J, Miedema B, Ota D, Sargent D, National Cancer Institute Expert Panel (2001) Guidelines 2000 for colon and rectal cancer surgery. J Natl Cancer Inst 93(8):583-596

10. Monson JR, Weiser MR, Buie WD, Chang GJ, Rafferty JF, Buie WD et al (2013) Practice parameters for the management of rectal cancer (revised). Dis Colon Rectum 56(5):535-550

11. Xynos E, Tekkis P, Gouvas N, Vini L, Chrysou E, Tzardi M, Vassiliou V, Boukovinas I, Agalianos C, Androulakis N, Athanasiadis A, Christodoulou C, Dervenis C, Emmanouilidis C, Georgiou P, Katopodi O, Kountourakis P, Makatsoris T, Papakostas P, Papamichael D, Pechlivanides G, Pentheroudakis G, Pilpilidis I, Sgouros J, Triantopoulou C, Xynogalos S, Karachaliou N, Ziras N, Zoras O, Souglakos J, [the Executive Team on behalf of the Hellenic Society of Medical Oncologists (HeSMO)] (2016) Clinical practice guidelines for the surgical treatment of rectal cancer: a consensus statement of the Hellenic Society of Medical Oncologists (HeSMO). Ann Gastroenterol 29(2):103126

12. You YN, Hardiman KM, Bafford A, Poylin V, Francone TD, Davis $\mathrm{K}$, et al. The American Society of Colon and Rectal Surgeons Clinical Practice Guidelines for the Management of Rectal Cancer. Ovid Technologies (Wolters Kluwer Health); 2020. p. 1191-222

13. Canessa CE, Miegge LM, Bado J, Silveri C, Labandera D (2004) Anatomic study of lateral pelvic lymph nodes: implications in the treatment of rectal cancer. Dis Colon Rectum 47(3):297-303

14. Atef Y, Koedam TW, van Oostendorp SE, Bonjer HJ, Wijsmuller AR, Tuynman JB (2019) Lateral Pelvic Lymph Node Metastases in Rectal Cancer: A Systematic Review. World J Surg 43(12):31983206
15. Christou N, Meyer J, Toso C, Ris F, Buchs NC (2019) Lateral lymph node dissection for low rectal cancer: Is it necessary? World J Gastroenterol 25(31):4294-4299

16. Otero de Pablos J, Mayol J (2020) Controversies in the Management of Lateral Pelvic Lymph Nodes in Patients With Advanced Rectal Cancer: East or West? Frontiers in Surgery 6(January): 1-8

17. Georgiou PA, Mohammed Ali S, Brown G, Rasheed S, Tekkis PP (2017) Extended lymphadenectomy for locally advanced and recurrent rectal cancer. Int J Color Dis 32(3):333-340

18. Cheng H, Deng Z, Wang ZJ, Zhang W, Su JT (2011) Lateral lymph node dissection with radical surgery versus single radical surgery for rectal cancer: a meta-analysis. Asian Pac J Cancer Prev 12(10): 2517-2521

19. Ma P, Yuan Y, Yan P, Chen G, Ma S, Niu X, et al. The efficacy and safety of lateral lymph node dissection for patients with rectal cancer: A systematic review and meta-analysis. Asian Journal of Surgery. 2020(xxxx)

20. Hajibandeh S, Hajibandeh S, Matthews J, Palmer L, Maw A (2020) Meta-analysis of survival and functional outcomes after total mesorectal excision with or without lateral pelvic lymph node dissection in rectal cancer surgery. Surgery. 168(3):486-496

21. Longchamp G, Meyer J, Christou N, Popeskou S, Roos E, Toso C, Buchs NC, Ris F (2020) Total mesorectal excision with and without lateral lymph node dissection: a systematic review of the literature. Int J Color Dis 35(7):1183-1192

22. Xiang Gao, Cun Wang, Yong-Yang Yu et al. Lateral lymph node dissection reduces local recurrence of locally advanced lower rectal cancer in the absence of preoperative neoadjuvant chemoradiotherapy: A systematic review and meta-analysis, 21 September 2020, PREPRINT (Version 2) available at Research Square [https://doi. org/10.21203/rs.3.rs-42723/v2]

23. Law BZY, Yusuf Z, Ng YE, Aly EH (2020) Does adding lateral pelvic lymph node dissection to neoadjuvant chemotherapy improve outcomes in low rectal cancer? Int J Color Dis 35(8):13871395

24. Shea BJ, Reeves BC, Wells G, Thuku M, Hamel C, Moran J et al. AMSTAR 2: A critical appraisal tool for systematic reviews that include randomised or non-randomised studies of healthcare interventions, or both. BMJ (Online). 2017;358

25. Moher D, Liberati A, Tetzlaff J, Altman DG (2009) Preferred reporting items for systematic reviews and meta-analyses: the PRISMA statement. J Clin Epidemiol 62(10):1006-1012

26. JPT Higgins, Thomas J, Chandler J, Cumpston M, Li T, Page MJ, Welch VA (editors) Cochrane Handbook for Systematic Reviews of Interventions version 6.1 (updated September 2020). Cochrane, 2020. Available from www.training.cochrane.org/handbook

27. Sterne JA, Hernán MA, Reeves BC, Savović J, Berkman ND, Viswanathan M et al (2016) ROBINS-I: a tool for assessing risk of bias in non-randomised studies of interventions. Bmj. 355:i4919

28. McGuinness LA, Higgins JPT Risk-of-bias VISualization (robvis): An R package and Shiny web app for visualizing risk-of-bias assessments. Research Synthesis Methods. 2020;n/a(n/a)

29. Mantel N, Haenszel W (1959) Statistical Aspects of the Analysis of Data From Retrospective Studies of Disease. JNCI: Journal of the National Cancer Institute 22(4):719-748

30. Rücker G, Schwarzer G, Carpenter JR, Schumacher M (2008) Undue reliance on I2 in assessing heterogeneity may mislead. BMC Med Res Methodol 8(1):79

31. Kontopantelis E, Springate DA, Reeves D (2013) A re-analysis of the Cochrane Library data: the dangers of unobserved heterogeneity in meta-analyses. PLoS One 8(7):e69930

32. Otowa Y, Yamashita K, Kanemitsu K, Sumi Y, Yamamoto M, Kanaji S, Imanishi T, Nakamura T, Suzuki S, Tanaka K, Kakeji Y (2015) Treating patients with advanced rectal cancer and lateral 
pelvic lymph nodes with preoperative chemoradiotherapy based on pretreatment imaging. Onco Targets Ther 8:3169-3173

33. Dong XS, Xu HT, Yu ZW, Liu M, Cu BB, Zhao P, Wang XS (2003) Effect of extended radical resection for rectal cancer. World J Gastroenterol 9(5):970-973

34. Shirouzu K, Ogata Y, Araki Y, Sasatomi T, Nozoe Y, Nakagawa M et al (2001) Total Mesorectal Excision, Lateral Lymphadenectomy and Autonomic Nerve Preservation for Lower Rectal Cancer: Significance in the Long-term Follow-up Study. Kurume Med J 48(4):307-319

35. Havenga K, Enker WE, Norstein J, Moriya Y, Heald RJ, van Houwelingen HC, van de Velde CJH (1999) Improved survival and local control after total mesorectal excision or D3 lymphadenectomy in the treatment of primary rectal cancer: an international analysis of 1411 patients. Eur J Surg Oncol 25(4):368-374

36. Michelassi F, Block GE (1992) Morbidity and mortality of wide pelvic lymphadenectomy for rectal adenocarcinoma. Dis Colon Rectum 35(12):1143-1147

37. Hojo K, Sawada T, Moriya Y (1989) An analysis of survival and voiding, sexual function after wide iliopelvic lymphadenectomy in patients with carcinoma of the rectum, compared with conventional lymphadenectomy. Dis Colon Rectum 32(2):128-133

38. Michelassi F, Block GE, Vannucci L, Montag A, Chappell R (1988) A 5- to 21-year follow-up and analysis of 250 patients with rectal adenocarcinoma. Ann Surg 208(3):379-389

39. Enker WE, Pilipshen SJ, Heilweil ML, Stearns MW Jr, Janov AJ, Hertz RE et al (1986) En bloc pelvic lymphadenectomy and sphincter preservation in the surgical management of rectal cancer. Ann Surg 203(4):426-433

40. Tsukamoto S, Fujita S, Ota M, Mizusawa J, Shida D, Kanemitsu Y, Ito M, Shiomi A, Komori K, Ohue M, Akazai Y, Shiozawa M, Yamaguchi T, Bando H, Tsuchida A, Okamura S, Akagi Y, Takiguchi N, Saida Y, Akasu T, Moriya Y (2020) Long-term follow-up of the randomized trial of mesorectal excision with or without lateral lymph node dissection in rectal cancer (JCOG0212). Br J Surg 107(5):586-594

41. Fujita S, Mizusawa J, Kanemitsu Y, Ito M, Kinugasa Y, Komori K, Ohue M, Ota M, Akazai Y, Shiozawa M, Yamaguchi T, Bandou H, Katsumata K, Murata K, Akagi Y, Takiguchi N, Saida Y, Nakamura K, Fukuda H, Akasu T, Moriya Y, Colorectal Cancer Study Group of Japan Clinical Oncology Group (2017) Mesorectal Excision with or Without Lateral Lymph Node Dissection for Clinical Stage II/III Lower Rectal Cancer (JCOG0212). Ann Surg 266(2):201-207

42. Fujita S, Akasu T, Mizusawa J, Saito N, Kinugasa Y, Kanemitsu Y, Ohue M, Fujii S, Shiozawa M, Yamaguchi T, Moriya Y, Colorectal Cancer Study Group of Japan Clinical Oncology Group (2012) Postoperative morbidity and mortality after mesorectal excision with and without lateral lymph node dissection for clinical stage II or stage III lower rectal cancer (JCOG0212): Results from a multicentre, randomised controlled, non-inferiority trial. The Lancet Oncology 13(6):616-621

43. Ito M, Kobayashi A, Fujita S, Mizusawa J, Kanemitsu Y, Kinugasa Y, Komori K, Ohue M, Ota M, Akazai Y, Shiozawa M, Yamaguchi T, Akasu T, Moriya Y, Colorectal Cancer Study Group of Japan Clinical Oncology Group (2018) Urinary dysfunction after rectal cancer surgery: Results from a randomized trial comparing mesorectal excision with and without lateral lymph node dissection for clinical stage II or III lower rectal cancer (Japan Clinical Oncology Group Study, JCOG0212). Eur J Surg Oncol 44(4): 463-468

44. Saito S, Fujita S, Mizusawa J, Kanemitsu Y, Saito N, Kinugasa Y, Akazai Y, Ota M, Ohue M, Komori K, Shiozawa M, Yamaguchi T, Akasu T, Moriya Y (2016) Male sexual dysfunction after rectal cancer surgery: Results of a randomized trial comparing mesorectal excision with and without lateral lymph node dissection for patients with lower rectal cancer: Japan Clinical Oncology Group Study JCOG0212. Eur J Surg Oncol 42(12):1851-1858

45. Nagawa H, Muto T, Sunouchi K, Higuchi Y, Tsurita G, Watanabe T, Sawada T (2001) Randomized, controlled trial of lateral node dissection vs. nerve-preserving resection in patients with rectal cancer after preoperative radiotherapy. Dis Colon Rectum 44(9):1274 1280

46. Oki E, Shimokawa M, Ando K, Murata A, Takahashi T, Maeda K, Kusumoto T, Munemoto Y, Nakanishi R, Nakashima Y, Saeki H, Maehara Y (2019) Effect of lateral lymph node dissection for mid and low rectal cancer: An ad-hoc analysis of the ACTS-RC (JFMC35-C1) randomized clinical trial. Surgery. 165(3):586-592

47. Nishizaki D, Hida K, Sumii A, Sakai Y, Konishi T, Akagi T et al (2019) Neoadjuvant chemoradiotherapy with/without lateral lymph node dissection for low rectal cancer: Which patients can benefit? Ann Oncol 30(October):v205-v20v

48. Ogura A, Konishi T, Cunningham C, Garcia-Aguilar J, Iversen H, Toda S, Lee IK, Lee HX, Uehara K, Lee P, Putter H, van de Velde CJH, Beets GL, Rutten HJT, Kusters M, on behalf of the Lateral Node Study Consortium (2019) Neoadjuvant (chemo)radiotherapy with total mesorectal excision only is not sufficient to prevent lateral local recurrence in enlarged nodes: Results of the multicenter lateral node study of patients with low ct3/4 rectal cancer. J Clin Oncol 37(1):33-43

49. Matsuda T, Sumi Y, Yamashita K, Hasegawa H, Yamamoto M, Matsuda Y, Kanaji S, Oshikiri T, Nakamura T, Suzuki S, Kakeji Y (2018) Outcomes and prognostic factors of selective lateral pelvic lymph node dissection with preoperative chemoradiotherapy for locally advanced rectal cancer. Int J Color Dis 33(4):367-374

50. Park BK, Lee SJ, Hur BY, Kim MJ, Chan Park S, Chang HJ, Kim DY, Oh JH (2018) Feasibility of selective lateral node dissection based on magnetic resonance imaging in rectal cancer after preoperative chemoradiotherapy. J Surg Res 232:227-233

51. Dev K, Veerenderkumar KV, Krishnamurthy S (2018) Incidence and Predictive Model for Lateral Pelvic Lymph Node Metastasis in Lower Rectal Cancer. Indian J Surg Oncol 9(2):150-156

52. Ishihara S, Kawai K, Tanaka T, Kiyomatsu T, Hata K, Nozawa H, Morikawa T, Watanabe T (2017) Oncological outcomes of lateral pelvic lymph node metastasis in rectal cancer treated with preoperative chemoradiotherapy. Dis Colon Rectum 60(5):469-476

53. Tamura H, Shimada Y, Kameyama H, Yagi R, Tajima Y, Okamura T, Nakano M, Nakano M, Nagahashi M, Sakata J, Kobayashi T, Kosugi SI, Nogami H, Maruyama S, Takii Y, Wakai T (2017) Prophylactic lateral pelvic lymph node dissection in stage IV low rectal cancer. World Journal of Clinical Oncology 8(5):412-419

54. Kim HJ, Choi GS, Park JS, Park SY, Cho SH, Lee SJ, Kang BW, Kim JG (2017) Optimal treatment strategies for clinically suspicious lateral pelvic lymph node metastasis in rectal cancer. Oncotarget. 8(59):100724-100733

55. Ozawa H, Kotake K, Hosaka M, Hirata A, Sugihara K (2016) Impact of Lateral Pelvic Lymph Node Dissection on the Survival of Patients with T3 and T4 Low Rectal Cancer. World J Surg 40(6): 1492-1499

56. Akiyoshi T, Toda S, Tominaga T, Oba K, Tomizawa K, Hanaoka Y, Nagasaki T, Konishi T, Matoba S, Fukunaga Y, Ueno M, Kuroyanagi H (2019) Prognostic impact of residual lateral lymph node metastasis after neoadjuvant (chemo)radiotherapy in patients with advanced low rectal cancer. BJS open 3(6):822-829

57. Kusters M, Beets GL, Van De Velde CJH, Beets-Tan RGH, Marijnen CAM, Rutten HJT et al (2009) A comparison between the treatment of low rectal cancer in japan and the netherlands, focusing on the patterns of local recurrence. Ann Surg 249(2): 229-235

58. Kobayashi H, Mochizuki H, Kato T, Mori T, Kameoka S, Shirouzu K, Sugihara K (2009) Outcomes of surgery alone for lower rectal 
cancer with and without pelvic sidewall dissection. Dis Colon Rectum 52(4):567-576

59. Shiozawa M, Akaike M, Yamada R, Godai T, Yamamoto N, Saito H, Sugimasa Y, Takemiya S, Rino Y, Imada T (2007) Lateral lymph node dissection for lower rectal cancer. Hepatogastroenterology. 54(76):1066-1070

60. Kim JC, Takahashi K, Yu CS, Kim HC, Kim TW, Ryu MH, Kim JH, Mori T (2007) Comparative outcome between chemoradiotherapy and lateral pelvic lymph node dissection following total mesorectal excision in rectal cancer. Ann Surg 246(5):754-762

61. Yano H, Saito Y, Takeshita E, Miyake O, Ishizuka N (2007) Prediction of lateral pelvic node involvement in low rectal cancer by conventional computed tomography. Br J Surg 94(8):10141019

62. Kyo K, Sameshima S, Takahashi M, Furugori T, Sawada T (2006) Impact of autonomic nerve preservation and lateral node dissection on male urogenital function after total mesorectal excision for lower rectal cancer. World J Surg 30(6): 1014-1019

63. Çöl C, Hasdemir O, Yalcin E, Guzel H, Tunc G, Bilgen K, Kucukpinar T (2005) The assessment of urinary function following extended lymph node dissection for colorectal cancer. Eur J Surg Oncol 31(3):237-241

64. Hasdemir O, Cöl C, Yalçin E, Tunç G, Bilgen K, Kuçukpinar T (2005) Local recurrence and survival rates after extended systematic lymph-node dissection for surgical treatment of rectal cancer. Hepatogastroenterology. 52(62):455-459

65. Matsuoka H, Masaki T, Sugiyama M, Atomi Y (2005) Impact of lateral pelvic lymph node dissection on evacuatory and urinary functions following low anterior resection for advanced rectal carcinoma. Langenbeck's Arch Surg 390(6):517-522

66. Fujita S, Yamamoto S, Akasu T, Moriya Y (2003) Lateral pelvic lymph node dissection for advanced lower rectal cancer. Br J Surg 90(12):1580-1585

67. Maeda K, Maruta M, Utsumi T, Sato H, Toyama K, Matsuoka H (2003) Bladder and male sexual functions after autonomic nerve- sparing TME with or without lateral node dissection for rectal cancer. Techniques in Coloproctology 7(1):29-33

68. Suzuki K, Muto T, Sawada T (1995) Prevention of local recurrence by extended lymphadenectomy for rectal cancer. Surg Today 25(9): 795-801

69. Moreira LF, Hizuta A, Iwagaki H, Tanaka N, Orita K (1994) Lateral lymph node dissection for rectal carcinoma below the peritoneal reflection. Br J Surg 81(2):293-296

70. Bray F, Ferlay J, Soerjomataram I, Siegel RL, Torre LA, Jemal A (2018) Global cancer statistics 2018: GLOBOCAN estimates of incidence and mortality worldwide for 36 cancers in 185 countries. CA Cancer J Clin 68(6):394-424

71. Albandar MH, Cho MS, Bae SU, Kim NK (2016) Surgical management of extra-regional lymph node metastasis in colorectal cancer. Expert Rev Anticancer Ther 16(5):503-513

72. Oh H-K, Kang S-B, Lee S-M, Lee SY, Ihn MH, Kim D-W, Park JH, Kim YH, Lee KH, Kim JS, Kim JW, Kim JH, Chang TY, Park SC, Sohn DK, Oh JH, Park JW, Ryoo SB, Jeong SY, Park KJ (2014) Neoadjuvant chemoradiotherapy affects the indications for lateral pelvic node dissection in mid/low rectal cancer with clinically suspected lateral node involvement: a multicenter retrospective cohort study. Ann Surg Oncol 21(7):2280-2287

73. Williamson JS, Quyn AJ, Sagar PM (2020) Rectal cancer lateral pelvic sidewall lymph nodes: a review of controversies and management. Br J Surg 107:1562-1569

74. Colorectal cancer - NICE guideline [NG151] - Published date: 29 January 2020

75. Chan DKH, Tan K-K, Akiyoshi T (2019) Diagnostic and management strategies for lateral pelvic lymph nodes in low rectal cancera review of the evidence. Journal of Gastrointestinal Oncology 10(6):1200-1206

Publisher's note Springer Nature remains neutral with regard to jurisdictional claims in published maps and institutional affiliations. 